\title{
DEVELOPMENT OF INTERACTIVE ONLINE-BASED TEACHING MATERIALS FOR PHYSICS SUBJECTS IN CLASS X VOCATIONAL SCHOOLS
}

\author{
Yusdarina, Irma Sakti
}

Physics Education Department, Universitas Muslim Maros, yusdarina@umma.ac.id

\begin{abstract}
Abstrak
Penelitian ini bertujuan mengembangkan produk pembelajaran berupa bahan ajar berbasis daring interaktif untuk siswa kelas $X$ mata pelajaran fisika materi pengukuran di SMK Muhammadiyah Bungoro. Jenis penelitian ini adalah penelitian pengembangan. Model yang digunakan dalam pengembangan ini dilakukan dalam 5 tahapan, yaitu: analisis (analyze), desain (design), pengembangan (development), pelaksanaan (implementation), dan evaluasi (evaluation). Hasil yang dicapai dalam penelitian adalah sebuah produk berupa bahan ajar berbasis daring interaktif yang diterapkan dalam pembelajaran Fisika SMK Kelas X. Hasil penilaian validasi ahli materi dan ahli media berada pada kategori sangat valid dengan nilai rata-rata 89,22 dan 84,17. Hasil analisis respon guru mata pelajaran dan respon siswa berda pada kategori sangat praktis dengan nilai rata-rata 95,0 dan . 84,48. Hasil evaluasi terhadap siswa menunjukkan ketuntasan secara klasikal dengan nilai rata-rata 83,60. Hal ini menunjukkan bahwa bahan ajar berbasis daring interaktif layak digunakan pada pembelajaran daring mata pelajaran fisika kelas $X$.
\end{abstract}

\begin{abstract}
This study aims to develop learning products in the form of interactive online-based teaching materials for class $X$ students of physics subject measurement materials at SMK Muhammadiyah Bungoro. This type of research is development research. The model used in this development is carried out in 5 stages, namely: analysis (analyze), design (design), development (development), implementation (implementation), and evaluation (evaluation). The results achieved in this study are a product in the form of interactive online-based teaching materials that are applied in learning Physics at SMK Class X. The results of the validation assessment of material experts and media experts are in the very valid category with an average value of 89.22 and 84.17. The results of the analysis of subject teacher responses and student responses are in the very practical category with an average value of 95.0 and. 84.48. The results of the evaluation of students showed classical completeness with an average value of 83.60. This shows that interactive online-based teaching materials are suitable for use in online learning for class $X$ physics subjects.
\end{abstract}

Kata kunci: Bahan ajar, bahan ajar interaktif, pembelajaran daring

\section{Pendahuluan}

Pembelajaran sekarang ini tidak lepas dari pemanfaatan teknologi . Hal ini dapat dilihat dari Proses pembelajaran jarak jauh atau daring yang memerlukan penguasaan ilmu teknologi bagi seorang guru agar pembelajaran jarak jauh tetap berjalan dengan efektif disaat pandemi seperti ini.

Diera perkembangan teknologi, pendidik dominan kesulitan dalam menciptakan suatu lingkungan belajar yang dapat membawa peserta didik menjadi lebih kreatif dan logis. Pembelajaran cenderung berpusat pada pendidik (teacher centered).
Pembelajaran seperti ini cenderung menghambat kreatifitas berpikir peserta didik terutama dalam mata pelajaran excat (Sulaiman, 2020)

Fisika sebagai bagian Ilmu Pengetahuan Alam (IPA) atau sains, berkaitan dengan cara mencari tahu tentang fenomena alam secara sistematis, sehingga fisika bukan hanya penguasaan kumpulan pengetahuan yang berupa fakta-fakta, konsep-konsep, atau prinsip-prinsip saja tetapi juga merupakan suatu proses penemuan. Proses pembelajaran menekankan pada pemberian pengalaman langsung untuk mengembangkan kompetensi agar mahasiswa menjelajahi dan memahami alam sekitar secara ilmiah (Swari, 
2018).

Fisika merupakan salah satu mata pelajaran yang diajarkan pada peserta didik jenjangSMK juga harus diajarkan dari rumah yang diistilahkan pembelajaran jarak jauh fisika (PJJ Fisika). Berdasarkan informasi yang diperoleh dari Peserta didik bahwa belajar fisika di kelas/ sekolah dengan bimbingan guru secara tatap muka saja sangat sulit untuk memahami fisika apalagi jika tidak ada pertemuan dengan guru, hanya belajar mandiri di rumah. Pernyataan peserta didik seperti itu harus dapat ditepis atau dihilangkan oleh guru. Pembelajaran jarak jauh fisika yang dilakukan memberikan tantangan tersendiri bagi para guru dan peserta didik. Guru dituntut kreatif dalam memberikan materi PJJ fisika sehingga peserta didik tidak hanya mengerjakan tugas akademik melainkan juga melakukan kegiatan menyenangkan agar keinginanbelajar peserta didik tetap tinggi.

Kenyataan dilapangan guru belum memanfaatkan teknologi dengan maksimal. Guru hanya memberikan materi kepada peserta didik dalam bentuk powerpoint, word ataupun PDF. Hal ini sesuai dengan hasil pengamatan di SMK Muhammadiyah bungoro yaitu proses pembelajaran jarak jauh atau daring yang dilakukan oleh guru hanya sebatas pemberian materi dan penugasan tanpa adanya media yang menarik perhatian peserta didik untuk belajar mandiri di rumah. Aplikasi yang digunakan pun sebagian besar hanya aplikasi Whatshapp dan sebagian kecilmenggunakan aplikasi classroom dan belajar melalui youtube channel yang dibuat oleh guru mata pelajaran. Namun pembelajaran secara daring dinilai kurang efektif jika hanya mengandalkan komunikasi via WhatsApp yang terbatas hanya pengiriman gambar soal atau teks soal dalam grup-grup kelas yang dikirimkan oleh guru mata pelajaran masing-masing. Tidak terjadi komunikasi dua arah antara peserta didik dan guru. Sehingga dibutuhkan sistem yang terintegrasi antara peserta didik dan guru sehingga pembelajaran bisa lebih interaktif dan real- time. Solusi dari pemasalahan itu adalah memberikan bahan ajar berbasis daring interaktif yang dapat dipelajari oleh peserta didika secara mandiri di rumah.
Berdasarkan hasil observasi yang dilakukan di SMK Muhammadiyah Bungoro pada tanggal 12 juli 2021, bahan ajar yang digunakan oleh guru maupun siswa pada proses pembelajaran daring berupa buku cetak dan buku pendukung lainnya yang disediakan oleh sekolah. Pada umumnya buku yang digunakan tidak interaktif, tidak menekankan pada pemahaman konsep, tidak bersifat visual, tampilan serta warna gambar yang disajikan dalam buku tersebut tidak menarik. Hal tersebut menyebabkan siswa kurang memahami konsep dan kesulitan dalam memecahkan masalah terhadap materi yang diajarkan.

Rendahnya pemahaman konsep fisika siswa berdampak pada hasil belajarnya. Hal ini ditunjukkan dengan data dari penilaian akhir semester genap tahun pelajaran 2020/2021 diperoleh nilai rata-rata $66,67 \%$ dengan kriteria ketuntasan minimal (KKM) yaitu 75. Dari persentase ketuntasan klasikal tersebut menunjukkan bahwa hasil belajar siswa di bawah KKM. Oleh karena itu, guru dan siswa membutuhkan sebuah bahan ajar yang interaktif yang lengkap baik dari segi materi, contoh soal maupun latihan soal terutama untuk materi yang bersifat abstrak maupun visual, sehingga mempermudah siswa dalam memahami konsep terhadap materi yang disajikan

Berdasarkan kondisi tersebut di atas, penulis mencoba memberikan solusi alternatif dan tertarik mengembangkan bahan ajar interaktif. Pengembangan bahan ajar berbasis daring interaktif didesain dengan mengkombinasikan beberapa media pembelajaran yang bersifat interaktif sehingga terjadi hubungan dua arah antara bahan ajar dengan peserta didik. Bahan ajar ini dapat mendukung kegiatan belajar mengajar guru dan peserta didik selama proses pembelajaran daring. Proses pembelajaran menjadi aktif dan interaktif serta membantu peserta didik untuk menjadi pelajar yang mandiri.

Penelitian ini bertujuan untuk menghasilkan bahan ajar fisika berbasis daring interaktif yang valid, praktis dan efektif digunakan pada mata pelajaran fisika kelas X di SMK Muhammadiyah bungoro. 


\section{Metode}

Penelitian ini tergolong penelitian pengembangan. Dikatakan penelitian pengembangan karena penelitian ini menghasilkan sebuah rancangan baru berupa bahan ajar berbasis daring interaktif. Seperti yang dikemukakan oleh Sugiyono (2014) "Metode penelitian dan pengembangan adalah metode penelitian yang digunakan untuk menghasilkan produk tertentu, dan menguji keefektifan produk tersebut"

Setelah produk pengembangan ini dinyatakan valid dan dinilai layak untuk dikenalkan kepada peserta didik, maka peneliti memperkenalkan hasil produk pengembangan yang peneliti kembangkan. Bahan ajar yang dikembangkan diujicobakan di Kelas X di SMK Muhammadiyah Bungoro kabupaten Pangkep pada tahun pelajaran 2021/2022.

Peneliti mendesain sebuah media pembelajaran berupa bahan ajar berbasis daring interaktif dengan menggunakan model ADDIE. Peneliti menggunakan model ini dikarenakan sederhana dan mudah dipelajari serta strukturnya yang sistematis dimana hanya terdiri dari 5 tahap yaitu analisis (analyze), desain (design), pengembangan (development), pelaksanaan (implementation), dan evaluasi (evaluation).

Data penelitian dianalisis menggunakan analisis statistik deskriptif. Statistik deskriptif dapat berbentuk diagram batang, diagram serabi, mode, median, mean, dan variabillitas ukuran (Arikunto, 2013) Menggunakan analisis statistik deskriptif, data penelitian dapat dianalisis sebagai berikut.

\section{Analisis Data Kevalidan}

Data hasil validasi untuk media pembelajaran dianalisis dengan mempertimbangkan masukan, komentar dan saran-saran dari para validator. Hasil analisis tersebut disajikan untuk mengetahui tingkat kevalidan dari produk yang dikembangkan. Analisis validitas menggunakan Skala Likert dengan langkah-langkah:

a. Memberikan skor untuk setiap item jawaban sangat setuju (4), setuju (3), tidak setuju (2) dan sangat sangat tidak setuju (1). b. Menjumlahkan skor total tiap validator untuk seluruh indikator.

c. Pemberian nilai validitas dengan cara menggunakan rumus:

$V=\frac{f}{N} \times 100 \%$

Keterangan:

$V=$ Nilai Akhir

$f=$ Perolehan Skor

$N=$ Skor Maksimum

Hasil penentuan kategori tingkat kevalidan berdasarkan tabel 1 berikut ini:

Tabel 1 Kategori Tingkat Kevalidan

\begin{tabular}{ll}
\hline Interval & Kategori \\
\hline $81-100$ & Sangat Valid \\
$61-80$ & Valid \\
$41-60$ & Cukup Valid \\
$21-40$ & Tidak Valid \\
$0-20$ & Sangat Tidak Valid \\
\hline \multicolumn{2}{c}{ Sumber: (Dr. Riduwan, 2019) }
\end{tabular}

2. Analisis Data Kepraktisan

Suatu produk media pembelajaran dikatakan praktis jika siswa dapat menggunakan media pembelajaran tersebut dalam pembelajaran secara praktis dan efisien. Kepraktisan produk dianalisis berdasarkan angket yang telah diisi oleh siswa. Analisis data praktikalitas media pembelajaran berdasarkan angket siswa dengan langkahlangkah berikut ini:

a. Memberikan skor untuk setiap item jawaban sangat setuju (4), setuju (3), tidak setuju (2) dan sangat sangat tidak setuju (1).

b. Menjumlahkan skor total untuk seluruh indikator.

c. Pemberian nilai praktikalitas dengan cara menggunakan rumus:

$P=\frac{f}{N} \times 100 \%$

Keterangan:

$$
\begin{aligned}
& P=\text { Nilai Akhir } \\
& f=\text { Perolehan Skor } \\
& N=\text { Skor Maksimum }
\end{aligned}
$$

Hasil penentuan kategori tingkat kevalidan berdasarkan tabel 2 berikut ini: 
Tabel 2 Kategori Tingkat Kepraktisan

\begin{tabular}{ll}
\hline Interval & Kategori \\
\hline $81-100$ & Sangat Praktis \\
$61-80$ & Praktis \\
$41-60$ & Cukup Praktis \\
$21-40$ & Tidak Praktis \\
$0-20$ & Sangat Tidak Praktis \\
\hline
\end{tabular}

Sumber : (Dr. Riduwan, 2019)

\section{Analisis Data Keefektifan}

Keefektifan produk yang dikembangkan dianalisis berdasarkan data pengukuran tes hasil belajar siswa setelah pembelajaran dengan langkah-langkah berikut ini:

a. Memberikan skor untuk setiap item jawaban sangat setuju (4), setuju (3), tidak setuju (2) dan sangat sangat tidak setuju (1).

b. Menjumlahkan skor total untuk seluruh indikator.

c. Pemberian nilai efektivitas dengan cara menggunakan rumus:

$E=\frac{f}{N} \times 100 \%$

Keterangan:

$$
\begin{aligned}
& E=\text { Nilai Akhir } \\
& f=\text { Perolehan Skor } \\
& N=\text { Skor Maksimum }
\end{aligned}
$$

Tabel 3 Kategori Tingkat Keefektifan

\begin{tabular}{cc}
\hline Interval & Kategori \\
\hline $81-100$ & Sangat Efektif \\
$61-80$ & Efektif \\
$41-60$ & Cukup Efektif \\
$21-40$ & Tidak Efektif \\
$0-20$ & Sangat Tidak Efektif \\
\hline
\end{tabular}

Sumber: (Dr. Riduwan, 2019)

\section{Hasil dan Pembahasan}

Hasil pengembangan bahan ajar berbasis daring interaktif mengikuti prosedur pengembangan model ADDIE melalui 5 tahapan, yaitu: analisis (analyze), desain (design), pengembangan (development), pelaksanaan (implementation), dan evaluasi (evaluation). Produk yang dihasilkan adalah bahan ajar berbasis daring interaktif yang diterapkan dalam pembelajaran Fisika Kelas X SMK Muhammadiyah Bungoro.

Pada tahap pengembangan ini bertujuan untuk menghasilkan bahan ajar yang telah direvisi sehingga layak digunakan dalam penelitian atau diujicobakan. Kegiatan yang dilakukan pada tahap ini adalah validasi ahli. Hasil kegiatan dalam tahap pengembangan menjadi acuan untuk menilai apakah bahan ajar yang telah dikembangkan memenuhi kriteria valid, efektif dan efesien.

Berdasarkan data hasil penilaian oleh dua validator yaitu orang yang dipandang ahli dalam bidang fisika diperoleh hasil validasi ahli materi dengan nilai rata-rata 89,22. Sedangkan hasil review ahli media meliputi aspek tampilan, penggunaan dan pemanfaatan dengan nilai ratarata 84,17 . Hal ini menunjukkan bahwa bahan ajar fisika berbasis daring interaktif berada pada kategori sangat valid dan sudah layak diimplementasikan pada kegiatan pembelajaran mata pelajaran fisika kelas X materi pengukuran.

Kriteria praktis dilihat berdasarkan hasil analisis dari angket respon siswa dan angket respon guru. Hasil analisis data menunjukkan bahwa nilai ratarata untuk respon siswa adalah 84,48 berada pada kategori sangat praktis dan nilai rata-rata respon guru adalah 95,0 dan berada pada kategori sangat praktis. Dengan demikian, produk yang dikembangkan memenuhi kriteria sangat praktis. Hal ini menunjukkan bahwa guru dapat menerima konsep bahan ajar yang dikembangkan. Bahan ajar ini dinilai dapat menunjang pembelajaran daring karena peserta didik dapat belajar mandiri melalui laptop atau handpone yang digunakan dimana saja.

Kriteria efektif dilihat berdasarkan hasil analisis tes hasil belajar siswa. Hasil analisis data menunjukkan nilai rata-rata 83,60 atau berada kriteria sangat efektif yang berarti bahwa bahan ajar fisika berbasis daring interaktif yang digunakan efektif digunakan dalam pembelajaran daring khusus untuk mata pelajaran fisika materi pengukuran.

Guru dan siswa memberika tanggapan yang sangat baik terhadap bahan ajar fisika berbasis daring interaktif yang dikembangkan. Bahan ajar ini dinilai telah sesuai dengan kebutuhan siswa selama pembelajaran daring pada mata pelajaran fisika materi pengukuran. Menurut siswa, bahan ajar yang dikembangkan sangat menarik karena 
dilengkapi dengan gambar ilustrasi vidio animasi, rangkuman materi, tes formatif yang atraktif dan tombol navigasi yang memudahkan siswa dalam menggunakan bahan ajar tersebut. Adanya video animasi rangkuman materi pada bahan ajar memberikan motivasi belajar bagi siswa dan tes formatif atraktif dapat memudahkan proses evaluasi belajar. Bahan ajar interaktif juga dapat digunakan secara offline melalui komputer, laptop ataupun hp sehingga dapat meringankan kuota internet siswa.

Produk bahan ajar interaktif dinilai efektif dalam meningkatkan pemahaman konsep, karena materi yang disajikan selain menggunakan teks dan gambar, juga dilengkapi dengan animasi dan video materi yang memvisualisasi materi pengukuran. Hal tersebut didukung oleh pendapat Rogness (dalam nurkhaerunnisa, 2017), yang menyatakan bahwa penggunaan visualisasi dapat membantu siswa dalam meningkatkan pemahaman konsep.

\section{Kesimpulan}

Berdasarkan hasil penelitian yang telah dilakukan pada siswa kelas X SMK Muhammadiyah Bungoro dapat diambil kesimpulan bahwa bahan ajar berbasis daring interaktif yang dikembangkan dapat diterapkan pada proses pembelajaran daring mata pelajaran fisika kelas X. Profil bahan ajar yang dikembangkan telah memenuhi kriteria kevalidan, kepraktisan dan keefektifan, yaitu : (1) Sangat valid berdasarkan penilaian ahli materi dan ahli media, (2) Sangat praktis beradasarkan hasil analisis respon guru mata pelajaran dan respon siswa, (3) efektif karena ketuntasan klasikal telah tercapai dan respon siswa terhadap pembelajaran positif. Produk bahan ajar interaktif ini diharapkan dapat menjadi bahan ajar alternatif bagi siswa dalam meningkatkan pemahaman materi, kemandirian belajar, dan motivasi belajar siswa dalam proses pembelajaran daring mata pelajaran fisika.

\section{Daftar Pustaka}

Afriansyah, Fahmi.M. \& Heni Pujiastuti. (2020). Pengembangan Bahan Ajar Matematika berbasis Virtual Learning dengan Gnomio. Jurnal Pendidikan Matematika, Vol. 11(2), 179- 188.

Alimin, Alif dan Hansi Effendi. (2020). Pengembangan Modul Pembelajaran Berbasis Daring Pada Mata Diklat Instalasi Penerangan Listrik Kelas XI Di Sekolah Menegah Kejuruan. Journal of Multidisciplinary Research and Development, Volume 2, Issue 4. https://jurnal.ranahresearch.com.

Ali Mudlofar. (2012). Aplikasi Pengembangan Kurikulum Satuan Tingkat Guruan dan Bahan Ajar dalam Guruan Islam. Jakarta: Rajawali Pers. hlm. 128.

Arifi n, A. Sjaeful. (2016). The Development Of Air-Theme Integrated Science Teaching Material Using Four Steps Teaching Material Development. Jurnal Pendidikan Fisika Indonesia 12 (1), 8-18.

Aziiza, A.A. , Syaad.P \& Triyanna. W. (2018).Pengembangan bahan ajar interaktif pada matapelajaran sistem komputer berbasis PBL untuk SMK. Jurnal Teknologi, Elektro, dan Kejuruan Vol.28 Issue 2, p166-176. http://journal2.um.ac.id/index.php/tekno

Febrianti, K.V., Fauzi Bakri dan Hadi Nasbey. (2017). Pengembangan Modul Digital Fisika Berbasis Discovery Learning Pada Pokok Bahasan Kinematika Gerak Lurus. Jurnal Wahana Pendidikan Fisika (2017) Vol.2 No.2 : 18-26.

Ika Lestari. (2013). Pengembangan BahanAjar Berbasis Kompetensi (Sesuai dengan Kurikulum Tingkat Satuan Pendidikan). Padang: Akademia Permata.

Mahadiraja, Dirat dan Syamsuarni. (2020). Pengembangan Modul Pembelajaran Berbasis Daring pada Mata Pelajaran Instalasi Penerangan Listrik Kelas XI 
Teknik Instalasi Tenaga Listrik T.P 2019/2020 di SMK Negeri 1 Pariaman. JTEV (Jurnal Teknik Elektro Dan Vokasional) Vol 6 No 01.

http://ejournal.unp.ac.id/index.php/jtev/ind $\underline{\text { ex }}$

Minarni, Affan Malik dan Fuldiaratman. (2019). Pengembangan Bahan Ajar Dalam Bentuk Media Komik Dengan 3D Page Flip Pada Materi Ikatan Kimia Jurnal Inovasi Pendidikan Kimia, Vol 13, No 1, 2295 2306

Nurdyansyah. N., Andiek Widodo. (2015). Manajemen Sekolah Berbasis ICT. Sidoarjo: Nizamia Learning Center.

Prastowo, A. (2012). Panduan Kreatif Membuat Bahan Ajar Inovatif. Yogyakarta: DIVA Press.

2014. Panduan Kreatif Membuat Bahan Ajar Inovatif. Yogyakarta: Diva Press.

Purmadi, A. dan Herman D.S.(2016). Pengembangan bahan ajar berbasis web Berdasarkan gaya belajar siswa untuk mata pelajaran fisika. Jurnal Inovasi Teknologi Pendidikan Vol. 3, No 2, 151165.

Risnajayanti dan Silfiani. (2021). Pelaksanaan Pembelajaran Daring. Jurnal Pendidikan Anak Usia Dini.

Salma. (2021). Pengertian, Kendala, Manfaat dan Strategi Pembelajaran Daring. Diakses pada 22 September 2021, dari

https://penerbitdeepublish.com/pembelajar an-daring/
Smaragdina, Ahmad. A.,dkk. (2020). Pelatihan Pemanfaatan dan Pengembangan Bahan Ajar Digital Berbasis Multimedia Interaktif untuk Menghadapi Era Revolusi Industri 4.0. 2020. Jurnal Karinov, Vol.3 No. 1.

Sugiyono. (2014). Metode Penelitian Pendidikan. Bandung: Alfabeta.

Sulaiman, Umar. Dkk. (2020). Pengembangan Multimedia Interaktif Fisika Berbasis Mobile Learning Penggunaan Website Builde. Jurnal Pendidikan Fisika, Vol. 8 No. 2.

http://journal.uinalauddin.ac.id/indeks.php/ PendidikanFisika

Swari, Wahyu D. dan Basry Yadi T. (2018). Pengembangan Handout Interaktif Berbasis Contextual Teaching And Learning (CTL) Pada Pokok Bahasan Listrik. Jurnal Pendidikan Fisika, Vol. 6 No. 1. http://journal.uinalauddin.ac.id/indeks.php/PendidikanFisik $\underline{\mathrm{a}}$

Waruwu, Fince Tinus dan Sarwandi. (2021). Pengembangan Bahan Ajar Interaktif Melalui Pembelajaran Daring Di SMP IT Al-Munadi. Jurnal Abdimas Budi Darma. Vol 1 No. 2: 64-68 